Article

\title{
Psychological Stress Accompanied by a Low-Variety Diet Is Positively Associated with Type 2 Diabetes in Middle-Aged Adults
}

\author{
Yoonjin Shin $(1)$ and Yangha Kim *10 \\ Department of Nutritional Science and Food Management, Ewha Womans University, Seoul 03760, Korea; \\ yjin19@hotmail.com \\ * Correspondence: yhmoon@ewha.ac.kr; Tel.: +82-2-3277-3101
}

Received: 2 August 2020; Accepted: 26 August 2020; Published: 27 August 2020

\begin{abstract}
Psychological stress is generally known to affect dietary intakes and cause chronic diseases. This study aims to investigate the association between psychological stress and the risk of type 2 diabetes in relation to dietary variety. A total of 126,405 middle-aged adults were enrolled in the Korean Genome and Epidemiology Study. Stress levels were measured using the psychosocial well-being index. Dietary variety score (DVS) was defined as the number of different foods consumed over a day. Stress levels were positively associated with the risks of diabetes (odds ratio (OR) for tertile 3 compared with tertile 1, men: OR $=1.34$ (95\% CI: 1.24-1.45); women: OR = $1.29(1.19-1.4)$ ). As the stress levels rose, the intake of grains increased, and the intake of fruits and vegetables decreased. Participants with higher stress levels showed lower DVS than those with lower stress levels. Furthermore, participants with higher stress levels and lower DVS had a significantly higher OR for diabetes than those with lower stress levels and higher DVS (men: OR $=1.83$ (1.58-2.12); women: $\mathrm{OR}=1.85(1.59-2.51)$ ). These results suggest that the high risk of type 2 diabetes for people with high stress levels may be associated with low dietary variety.
\end{abstract}

Keywords: psychological stress; type 2 diabetes; dietary variety score; low-variety diet

\section{Introduction}

Psychological stress is widely used to indicate the negative emotional, behavioral, and biological response to a perceived threat. A small amount of stress can be desirable, beneficial, and even healthy [1]. However, excessive or prolonged psychological stress may influence the pathogenesis of physical disease. Stress induces chronic activation of the neuroendocrine pathways that secrete adrenaline, noradrenaline, and cortisol. These hormones affect the body's sensitivity to insulin secretion and may interfere with normal blood sugar control, leading to diabetes [2].

Type 2 diabetes is a growing global health problem, and the number of people with diabetes is expected to double between 2000 and 2030 [3]. In Korea, the prevalence of diabetes in individuals aged 30 years has increased from $8.6 \%$ in 2001 to $11.0 \%$ in 2013 [4]. Due to prolonged lifespan, the incidence of diabetes is expected to increase more than previously anticipated. The first-line therapy for individuals with diabetes is known as lifestyle modification, involving diet [5]. Therefore, to reduce diabetes epidemics, individual efforts are needed to determine the modifiable factors that can affect their lifestyle and eating habits.

Dietary variety refers to the total number of different food items that are consumed individually for a certain period of time and is a major aspect of diet quality [6]. Eating a more varied diet is known to be related to higher nutritional adequacy; thus, several dietary guidelines have highlighted the value of eating a variety of foods $[7,8]$. According to a previous study, a greater dietary variety is 
related to a lower intake of refined grains and a higher intake of fruits and vegetables [9]. Moreover, a greater dietary variety was reported to have a protective effect against chronic diseases, including metabolic syndrome, cardiovascular disease, and cancer [10-12]. Therefore, dietary variety is supposed to improve nutritional status and reduce the risk of disease.

According to a 35-year follow-up study of middle-aged Swedish men, perceived stress is associated with a higher incidence of type 2 diabetes [13]. In addition, a Japanese cohort of men and women showed that the risk of diabetes increased by $50 \%$ in relation to perceived stress during a 10-year follow-up [14]. Collectively, these studies support the positive association between chronic psychological stress and the risk of diabetes. However, to our knowledge, no previous study has evaluated whether stress status may affect dietary variety and its relation to the prevalence of diabetes. Therefore, we aim to evaluate the association between stress and risk of diabetes in relation to dietary variety among middle-aged adults who participated in the Korean Genome and Epidemiology Study (KoGES).

\section{Materials and Methods}

\subsection{Study Population}

KoGES is a consortium project of population-based cohort studies aimed at investigating the genetic and environmental risk factors of common complex diseases found in the Korean population [15]. KoGES includes the Health Examinees (HEXA) Study and the Cardiovascular Disease Association Study (CAVAS), which consist of participants aged 40 years at baseline who were recruited from the national health examinee registry. We combined the data of the HEXA study $(n=173,357)$ and CAVAS ( $n=28,338$ ), conducted from 1 January 2004 to 31 December 2013. Initially, 201,695 individuals were recruited at baseline. Among them, only middle-aged adults $(n=174,131)$ were included in the study. Participants who did not complete the assessment of stress levels $(n=13,498)$, who did not have biochemical profiles $(n=5183)$, or who reported implausibly low or high intakes of energy $(<500$ or $4000 \mathrm{kcal} /$ day; $n=3074)$ were excluded. Participants who had self-reported diagnoses of cancer, cardiovascular disease, liver disease, and stomach disease were also excluded $(n=6628)$. Thus, 126,279 middle-aged adults (42,945 men and 83,334 women) were included in our final analyses. This study was approved by the Institutional Review Board of Ewha Womans University (No. 2019-0003, January 2019), and the procedures were performed in accordance with the Helsinki Declaration of 1975, as revised in 2008.

\subsection{Assessment of Stress Levels}

The psychological stress level of participants was measured using the psychological well-being index short form (PWI-SF) based on the General Health Questionnaires [16] and developed by Chang [17]. Its reliability and validity have been established for Korean laborers and the general public [17]. Respondents score each item using a four-point Likert scale, ranging from "strongly disagree" (0) to "strongly agree" (3); their scores were summed to determine the levels of stress, with higher scores indicating higher stress levels. In this study, participants were divided into three groups based on the tertile points of the score.

\subsection{Assessment of Dietary Intake}

Well-trained interviewers obtained the dietary data using a semiquantitative food-frequency questionnaire (SQFFQ) at the survey sites, including national and international medical schools, hospitals, and health institutions. Each participant provided the frequency of their average intake of 106 types of foods over a 12-month period (on a 9-point scale, ranging from "never" to $\geq 3$ servings/d) and the average intake quantity (on a 3-point scale: "less" ( 0.5 serving), a standard amount (1 serving), or "more" (1.5 servings)) according to questions from SQFFQ, developed and validated by KoGES [18,19]. Daily average food and nutrient intakes were calculated using a weighted frequency per day and a 
portion size per unit. The nutrient database of the Korean Nutrition Society was used to convert food intake into nutrients [20].

\subsection{Dietary Variety Score}

To evaluate the diversity of food intake, the dietary variety score (DVS) was calculated by counting the number of different food items consumed over a day by a nutritionist. The method was originally devised by Randall et al. [21], and this study modified the method reported by Choi et al. [22]. Food consumed several times during the period was counted only once. Each time another food is added, the DVS is increased by 1 point. Foods with the same main ingredients, such as pork belly and pork roast, were considered one food. The possible totals $(n=86)$ reflect all kinds of foods currently consumed in this study.

\subsection{Classification of Diabetes}

Type 2 diabetes was defined as a self-reported previous diagnosis by a physician, use of oral hypoglycemic agents or insulin, or a fasting glucose concentration of $\geq 126 \mathrm{mg} / \mathrm{dL}$ based on the World Health Organization criteria [23].

\subsection{General Characteristics, Anthropometric Measurements, and Biochemical Variables}

Data on demographic characteristics, current drinker (yes, no), current smoker (yes, no), moderate physical activity (yes, no), education ( $<$ high school, $\geq$ high school), monthly income $(<2$ million KRW, $\geq 2$ million KRW), and history of disease were obtained using an interview-administered questionnaire. Height was measured with a stadiometer, and weight was measured using a metric system while the participants were wearing a patient gown with no shoes. Body mass index (BMI) was calculated as weight as kilograms divided by height in meters squared. Waist circumference $(\mathrm{cm})$ was measured half-way between the lowest rib margin and the iliac crest using a nonstretchable standard tape. Blood pressure was measured at least twice on the right arm using an automatic sphygmomanometer or standardized mercury. Blood samples were collected after fasting for more than $8 \mathrm{~h}$, and plasma concentrations of high sensitive C-reactive protein (hs-CRP), total cholesterol, HDL cholesterol, triacylglycerol (TG), and glucose were quantified using the enzyme method (ADVIA 1650 and ADVIA 1800; Siemens Healthineers, Deerfield, IL, USA). For participants with TG concentrations $<400 \mathrm{mg} / \mathrm{dL}$, LDL cholesterol was calculated as described by Friedewald [24].

\subsection{Statistical Analysis}

All statistical analyses were performed using SAS v9.4 (SAS Institute Inc., Cary, NC, USA), and $p$-values of 0.05 . Continuous variables were expressed as mean \pm standard error and categorical variables as percentages. The participants were categorized into tertiles for relative comparison of stress levels according to the PWI score. The general linear model and the Cochran-Mantel-Haenszel analysis were used to determine the differences in means and distribution of general characteristics and to test the linear trends according to stress levels. Variables that were statistically significant in univariate analysis or known as potentially important factors associated with dietary intake and stress-induced chronic disease were considered potential confounders and adjusted in the analysis. Multivariate logistic regression analysis was applied to obtain ORs and 95\% CIs for the risk of diabetes. Dietary intakes were adjusted for total energy intake using the residual method.

\section{Results}

The participants' general characteristics according to stress levels are shown in Table 1. Men with higher stress levels tended to be slightly younger and had lower BMI than those with lower stress levels. On the contrary, women with higher stress levels were older and had a higher BMI. Men and women with higher stress levels tended to be earning less income, less educated, less likely to exercise, 
and more likely to drink and smoke. In men and women, those with higher stress levels exhibited higher concentrations of hs-CRP, fasting glucose, and HBA1c than those with lower stress levels.

Higher stress levels were associated with an increased prevalence of diabetes (Table 2). In multivariate analyses, men with the highest stress levels had higher odds of diabetes than those with the lowest stress levels (OR for tertile 3 compared with tertile 1, or $=1.34$ (95\% CI: 1.24-1.45) $p$-trend $<0.0001)$. Women with the highest stress levels also showed higher odds of diabetes $(\mathrm{OR}=1.29$ (95\% CI: $1.19-1.40) p$-trend $<0.0001)$.

Men and women with higher stress levels showed higher carbohydrate intakes than those with lower stress levels, but all other nutrient intakes were lower (Table 3). As stress levels increased, consumption of grains increased while consumption of fruits, vegetables, and protein foods decreased. Furthermore, men and women with higher stress levels showed a lower DVS than those with lower stress levels.

The prevalence and ORs of diabetes according to stress levels and DVS are presented in Table 4. In multivariate analyses, men and women with higher stress levels and a lower DVS had significantly higher odds of diabetes than those with lower stress levels and a higher DVS (men: OR $=1.83$ (95\% CI: 1.58-2.12); women: OR = 1.85 (95\% CI: 1.59-2.51)). 
Table 1. General characteristics of the subjects by tertiles of stress levels.

\begin{tabular}{|c|c|c|c|c|c|c|c|c|}
\hline \multirow[b]{2}{*}{ Variables } & \multicolumn{4}{|c|}{ Men } & \multicolumn{4}{|c|}{ Women } \\
\hline & $\begin{array}{l}\text { T1 (Lowest) } \\
(n=15,562)\end{array}$ & $\begin{array}{c}\text { T2 (Intermediate) } \\
(n=12,637)\end{array}$ & $\begin{array}{l}\text { T3 (Highest) } \\
(n=14,746)\end{array}$ & $p$-Trend & $\begin{array}{l}\text { T1 (Lowest) } \\
(n=28,227)\end{array}$ & $\begin{array}{l}\text { T2 (Intermediate) } \\
\quad(n=28,132)\end{array}$ & $\begin{array}{l}\text { T3 (Highest) } \\
(n=26,975)\end{array}$ & $p$-Trend \\
\hline Stress levels (score) & $7.9 \pm 0.03$ & $13.7 \pm 0.01$ & $23.0 \pm 0.04$ & $<0.0001$ & $8.9 \pm 0.02$ & $15.7 \pm 0.01$ & $26.1 \pm 0.03$ & $<0.0001$ \\
\hline Age (years) & $52.0 \pm 0.06$ & $51.4 \pm 0.06$ & $51.3 \pm 0.06$ & $<0.0001$ & $51.0 \pm 0.04$ & $50.9 \pm 0.04$ & $51.2 \pm 0.04$ & 0.020 \\
\hline Weight $(\mathrm{kg})$ & $70.4 \pm 0.07$ & $70.1 \pm 0.08$ & $69.5 \pm 0.08$ & $<0.0001$ & $58.1 \pm 0.04$ & $58.1 \pm 0.05$ & $58.1 \pm 0.05$ & 0.927 \\
\hline Waist circumstance $(\mathrm{cm})$ & $86.1 \pm 0.06$ & $85.7 \pm 0.07$ & $85.6 \pm 0.06$ & $<0.0001$ & $78.4 \pm 0.05$ & $78.4 \pm 0.05$ & $78.9 \pm 0.05$ & $<0.0001$ \\
\hline Body mass index $\left(\mathrm{kg} / \mathrm{m}^{2}\right)$ & $24.6 \pm 0.02$ & $24.5 \pm 0.02$ & $24.4 \pm 0.02$ & $<0.0001$ & $23.6 \pm 0.02$ & $23.7 \pm 0.02$ & $23.8 \pm 0.02$ & $<0.0001$ \\
\hline Systolic blood pressure $(\mathrm{mmHg})$ & $126.0 \pm 0.12$ & $125.9 \pm 0.13$ & $125.7 \pm 0.12$ & 0.241 & $120.8 \pm 0.09$ & $120.4 \pm 0.09$ & $120.7 \pm 0.10$ & 0.276 \\
\hline Diastolic blood pressure (mmHg) & $79.3 \pm 0.08$ & $79.2 \pm 0.09$ & $79.8 \pm 0.08$ & $<0.0001$ & $75.0 \pm 0.06$ & $74.9 \pm 0.06$ & $75.3 \pm 0.06$ & 0.0004 \\
\hline HBA1c (\%) & $5.7 \pm 0.01$ & $5.7 \pm 0.01$ & $5.8 \pm 0.01$ & $<0.0001$ & $5.6 \pm 0.01$ & $5.7 \pm 0.01$ & $5.7 \pm 0.01$ & $<0.0001$ \\
\hline Glucose $(\mathrm{mg} / \mathrm{dL})$ & $98.9 \pm 0.19$ & $99.2 \pm 0.21$ & $100.2 \pm 0.22$ & $<0.0001$ & $92.5 \pm 0.11$ & $92.8 \pm 0.11$ & $93.4 \pm 0.13$ & $<0.0001$ \\
\hline Current drinker (\%) & $11,600(74.6)$ & $9700(76.8)$ & $11,133(75.6)$ & 0.001 & 9351 (33.2) & $9241(32.9)$ & $9475(35.2)$ & $<0.0001$ \\
\hline Current smoker (\%) & $4871(31.3)$ & $4388(34.8)$ & $5895(40.0)$ & $<0.0001$ & $472(1.7)$ & $604(2.2)$ & $934(3.5)$ & $<0.0001$ \\
\hline Moderate exercise (\%) & $9167(59.0)$ & $6857(54.3)$ & $6786(46.1)$ & $<0.0001$ & $15,384(54.6)$ & $13,909(49.5)$ & $11,019(40.9)$ & $<0.0001$ \\
\hline Education ( $\geq$ high school, \%) & 11,971 (77.6) & $9889(78.9)$ & $10,490(71.8)$ & $<0.0001$ & $18,570(66.3)$ & $17,807(63.9)$ & $14,689(55.1)$ & $<0.0001$ \\
\hline Monthly income ( $\geq 2$ million KRW, \%) & $10,596(77.3)$ & $8632(77.7)$ & $8425(69.6)$ & $<0.0001$ & $17,408(71.2)$ & $16,362(69.6)$ & $12,627(60.2)$ & $<0.0001$ \\
\hline
\end{tabular}

HbA1c, hemoglobin A1c; hs-CRP, high sensitive C-reactive protein; KRW, Korean won. Values are expressed as means (SE) or percentage. The $p$-trend was obtained in general linear model analysis and Cochran-Mantel-Haenszel analysis, with adjustment for age.

Table 2. Odds ratios (95\% confidence intervals) for diabetes by tertiles of stress levels.

\begin{tabular}{|c|c|c|c|c|c|c|c|c|}
\hline \multirow[b]{2}{*}{ Variables } & \multicolumn{4}{|c|}{ Men } & \multicolumn{4}{|c|}{ Women } \\
\hline & $\begin{array}{l}\text { T1 (Lowest) } \\
(n=15,562)\end{array}$ & $\begin{array}{l}\text { T2 (Intermediate) } \\
(n=12,637)\end{array}$ & $\begin{array}{l}\text { T3 (Highest) } \\
(n=14,746)\end{array}$ & $p$-Trend & $\begin{array}{l}\text { T1 (Lowest) } \\
(n=28,227)\end{array}$ & $\begin{array}{l}\text { T2 (Intermediate) } \\
\quad(n=28,132)\end{array}$ & $\begin{array}{l}\text { T3 (Highest) } \\
(n=26,975)\end{array}$ & $p$-Trend \\
\hline Prevalence (\%) & $1660(10.7)$ & $1374(10.9)$ & $1883(12.8)$ & & $1472(5.2)$ & $1673(6.0)$ & $1929(7.2)$ & \\
\hline Unadjusted OR $(95 \%$ CI) & 1.00 & $1.02(0.95-1.10)$ & $1.23(1.14-1.32)$ & $<0.0001$ & 1.00 & $1.15(1.07-1.24)$ & $1.40(1.31-1.50)$ & $<0.0001$ \\
\hline Adjusted OR $(95 \% \mathrm{CI})$ & 1.00 & $1.07(0.99-1.17)$ & $1.34(1.24-1.45)$ & $<0.0001$ & 1.00 & $1.12(1.03-1.21)$ & $1.29(1.19-1.40)$ & $<0.0001$ \\
\hline
\end{tabular}

ORs ( $95 \%$ CIs) were conducted by logistic regression model. Adjusted ORs (95\% CIs) were obtained with adjustment for age, body mass index, alcohol intake, smoking, exercise, education

level, income status, and energy intake. The $p$-trend was obtained in general linear model analysis with adjustment for age, body mass index, alcohol intake, smoking, exercise, education level, income status, and energy intake. 
Table 3. Dietary intakes of the subjects by tertiles of stress levels.

\begin{tabular}{|c|c|c|c|c|c|c|c|c|}
\hline \multirow[b]{2}{*}{ Variables } & \multicolumn{4}{|c|}{ Men } & \multicolumn{4}{|c|}{ Women } \\
\hline & $\begin{array}{l}\text { T1 (Lowest) } \\
(n=15,562)\end{array}$ & $\begin{array}{c}\text { T2 (Intermediate) } \\
(n=12,637)\end{array}$ & $\begin{array}{l}\text { T3 (Highest) } \\
(n=14,746)\end{array}$ & $p$-Trend & $\begin{array}{l}\text { T1 (Lowest) } \\
(n=28,227)\end{array}$ & $\begin{array}{c}\text { T2 (Intermediate) } \\
(n=28,132)\end{array}$ & $\begin{array}{l}\text { T3 (Highest) } \\
(n=26,975)\end{array}$ & $p$-Trend \\
\hline Energy (kcal) & $1891.4 \pm 4.05$ & $1856.5 \pm 4.38$ & $1827.5 \pm 4.34$ & $<0.0001$ & $1742.6 \pm 2.99$ & $1706.1 \pm 2.99$ & $1659.8 \pm 3.25$ & $<0.0001$ \\
\hline Protein $(\mathrm{g})$ & $63.3 \pm 0.1$ & $62.5 \pm 0.1$ & $61.5 \pm 0.1$ & $<0.0001$ & $58.4 \pm 0.1$ & $57.4 \pm 0.1$ & $56.6 \pm 0.1$ & $<0.0001$ \\
\hline Carbohydrate (g) & $386.5 \pm 0.3$ & $387.1 \pm 0.3$ & $388.2 \pm 0.3$ & $<0.0001$ & $304.1 \pm 0.2$ & $305.5 \pm 0.2$ & $306.7 \pm 0.2$ & $<0.0001$ \\
\hline Fiber $(g)$ & $5.9 \pm 0.02$ & $5.7 \pm 0.02$ & $5.5 \pm 0.02$ & $<0.0001$ & $6.0 \pm 0.01$ & $5.8 \pm 0.01$ & $5.7 \pm 0.01$ & $<0.0001$ \\
\hline Vitamin A ( $\mu \mathrm{g}$ RE) & $500.5 \pm 2.4$ & $476.1 \pm 2.4$ & $466.6 \pm 2.4$ & $<0.0001$ & $492.6 \pm 1.7$ & $475.2 \pm 1.7$ & $468.9 \pm 1.8$ & $<0.0001$ \\
\hline Vitamin C (mg) & $102.9 \pm 0.4$ & $98.0 \pm 0.4$ & $92.0 \pm 0.4$ & $<0.0001$ & $116.8 \pm 0.3$ & $111.8 \pm 0.3$ & $107.7 \pm 0.4$ & $<0.0001$ \\
\hline Vitamin E (mg) & $8.3 \pm 0.02$ & $8.1 \pm 0.02$ & $8.0 \pm 0.02$ & $<0.0001$ & $8.2 \pm 0.02$ & $8.0 \pm 0.02$ & $8.0 \pm 0.02$ & 0.044 \\
\hline Potatoes $(\mathrm{g})$ & $19.5 \pm 0.3$ & $19.0 \pm 0.4$ & $19.3 \pm 0.4$ & 0.796 & $24.4 \pm 0.2$ & $24.6 \pm 0.2$ & $25.1 \pm 0.2$ & 0.001 \\
\hline Vegetables (g) & $312.8 \pm 1.4$ & $297.9 \pm 1.5$ & $291.5 \pm 1.5$ & $<0.0001$ & $310.6 \pm 1.0$ & $301.7 \pm 1.0$ & $298.7 \pm 1.1$ & $<0.0001$ \\
\hline Fruits (g) & $156.2 \pm 1.2$ & $146.0 \pm 1.3$ & $129.7 \pm 1.2$ & $<0.0001$ & $215.7 \pm 1.1$ & $203.7 \pm 1.1$ & $187.9 \pm 1.1$ & $<0.0001$ \\
\hline Protein foods (g) & $144.8 \pm 0.6$ & $142.8 \pm 0.6$ & $137.4 \pm 0.6$ & $<0.0001$ & $129.4 \pm 0.4$ & $124.8 \pm 0.4$ & $120.0 \pm 0.4$ & $<0.0001$ \\
\hline Meats (g) & $60.0 \pm 0.4$ & $61.0 \pm 0.5$ & $59.9 \pm 0.5$ & 0.268 & $46.4 \pm 0.3$ & $45.6 \pm 0.3$ & $45.8 \pm 0.3$ & 0.310 \\
\hline Fish and shellfish (g) & $43.2 \pm 0.3$ & $\begin{array}{l}\text { 1. } 1.0 \pm 0.0 \\
41.0 \pm 0.3\end{array}$ & $39.2 \pm 0.3$ & $<0.0001$ & $\begin{array}{l}\text { to. } 4 \pm 0.0 \\
41.5 \pm 0.2\end{array}$ & $\begin{array}{l}55.0 \pm 0.0 \\
40.1 \pm 0.2\end{array}$ & $\begin{array}{l}55.0 \pm 0.0 \\
38.6 \pm 0.2\end{array}$ & $<0.0001$ \\
\hline Eggs (g) & $15.0 \pm 0.3$ & $15.4 \pm 0.3$ & $16.1 \pm 0.3$ & 0.012 & $17.2 \pm 0.3$ & $17.0 \pm 0.2$ & $17.6 \pm 0.3$ & 0.001 \\
\hline Beans and products (g) & $31.5 \pm 0.2$ & $31.5 \pm 0.2$ & $30.6 \pm 0.2$ & 0.009 & $32.5 \pm 0.1$ & $31.9 \pm 0.1$ & $31.5 \pm 0.2$ & 0.343 \\
\hline
\end{tabular}

RE, retinol equivalent. Values were expressed as means (SE) and adjusted for total energy intake by using the residual method. The $p$-trend was obtained in general linear model analysis with adjustment for age, body mass index, alcohol intake, smoking, exercise, education level, and income status.

Table 4. Odds ratios (95\% confidence intervals) for diabetes by tertiles of stress levels and dietary variety score.

\begin{tabular}{|c|c|c|c|c|c|c|c|c|}
\hline \multirow[b]{2}{*}{ Variables } & \multicolumn{4}{|c|}{ Men } & \multicolumn{4}{|c|}{ Women } \\
\hline & $\begin{array}{l}\text { T1 (Lowest) } \\
(n=15,562)\end{array}$ & $\begin{array}{c}\text { T2 (Intermediate) } \\
(n=12,637)\end{array}$ & $\begin{array}{l}\text { T3 (Highest) } \\
(n=14,746)\end{array}$ & $P_{\text {stress }}$ for Trend & $\begin{array}{l}\text { T1 (Lowest) } \\
(n=28,227)\end{array}$ & $\begin{array}{l}\text { T2 (Intermediate) } \\
\quad(n=28,132)\end{array}$ & $\begin{array}{l}\text { T3 (Highest) } \\
(n=26,975)\end{array}$ & $P_{\text {stress }}$ for Trend \\
\hline \multicolumn{9}{|l|}{$\begin{array}{c}\text { Dietary variety score } \\
\text { T3 (Highest) }\end{array}$} \\
\hline Prevalence (\%) & $403(7.8)$ & $387(8.6)$ & 550 (11.6) & & $320(3.5)$ & $390(4.1)$ & $398(4.8)$ & \\
\hline $\begin{array}{c}\text { Adjusted OR ( } 95 \% \mathrm{CI}) \\
\text { T2 (Intermediate) }\end{array}$ & 1.00 (ref) & $1.14(0.98-1.34)$ & $1.64(1.42-1.90)$ & $<0.0001$ & 1.00 (ref) & $1.14(0.97-1.34)$ & $1.31(1.11-1.55)$ & 0.002 \\
\hline Prevalence $(\%)$ & $634(11.3)$ & $482(11.0)$ & $561(12.3)$ & & $537(5.3)$ & $564(5.9)$ & $550(6.6)$ & \\
\hline $\begin{array}{c}\text { Adjusted OR ( } 95 \% \text { CI) } \\
\text { T1 (Lowest) }\end{array}$ & $1.34(1.17-1.55)$ & $1.37(1.17-1.59)$ & $1.65(1.42-1.91)$ & 0.002 & $1.28(1.10-1.49)$ & $1.37(1.18-1.60)$ & $1.55(1.32-1.81)$ & 0.006 \\
\hline Prevalence $(\%)$ & $623(13.1)$ & 505 (13.4) & $772(14.1)$ & & $615(6.9)$ & $719(8.0)$ & $981(9.5)$ & \\
\hline Adjusted OR (95\% CI) & $1.47(1.27-1.71)$ & $1.62(1.38-1.89)$ & $1.83(1.58-2.12)$ & 0.001 & $1.36(1.17-1.59)$ & $1.59(1.37-1.86)$ & $1.85(1.59-2.15)$ & $<0.0001$ \\
\hline$P_{\text {Dvs for trend }}$ & $<0.0001$ & $<0.0001$ & 0.094 & & 0.0009 & $<0.0001$ & $<0.0001$ & \\
\hline
\end{tabular}

DVS, dietary variety score. OR, odds ratio; CI, confidence interval. ORs (95\% CIs) were conducted by logistic regression model. Adjusted ORs (95\% CIs) were obtained with adjustment for age, body mass index, alcohol intake, smoking, exercise, education level, income status, income status, and energy intake. The $p$-trend was obtained in general linear model analysis with adjustment for age, body mass index, alcohol intake, smoking, exercise, education level, income status, and energy intake. 


\section{Discussion}

This study investigates the association between psychological stress and the risk of type 2 diabetes in relation to dietary variety. The risk of diabetes was higher in participants with higher stress levels than those with lower stress levels. Participants with higher stress levels showed a higher intake of grains but a lower intake of fruits and vegetables than those with lower stress levels. Stress levels were associated with decreased DVS. Moreover, participants with higher stress levels and lower DVS had significantly higher ORs for diabetes than those with lower stress levels and higher DVS.

Stress has been associated with the development of type 2 diabetes $[13,25,26]$. Chronic activation of the hypothalamic-pituitary-adrenal axis due to long-term stress may interfere with cortisol release regulation. Cortisol stimulation has a direct impact on insulin sensitivity and reduces insulin secretion. Job strain, a form of psychological stress in the workplace, has been related to the high risk of type 2 diabetes in adults of European cohort studies [27]. Our study also shows that stress is associated with the risk of diabetes. To reduce the risk of diabetes, it is necessary to examine the possible modifiable factors, such as dietary habits, that are known to affect it.

As consuming a variety of food is known to be positively associated with the maintenance of health, dietary guidelines have long emphasized the value of eating a variety of foods [7,8]. Moving from a monotonous to a diverse diet can increase the probability of nutrient adequacy [28]. In this study, dietary variety was lower in participants with higher stress levels than those with lower stress levels. Stress is known to induce the activation of the sympathetic adrenal medulla system, along with the release of adrenaline and noradrenaline, which suppress appetite [29]. As appetite decreases, it can be assumed that the amount and number of food consumed decreases. Moreover, the reduction in the number of foods consumed is associated with a decrease in dietary diversity. This result is consistent with a prior study in which stress was inversely associated with dietary variety, which indicates the quality of a meal [30].

Lower dietary variety has been associated with higher intakes of refined grains and lower intakes of fruits and vegetables [9]. We found that participants with higher stress levels consumed more grains and had fewer fruits and vegetables. This finding indicates that stressful situations can lead to less consumption of side dishes and simple meals based on staple foods such as rice, bread, and noodles, thus increasing the intake of grains while reducing the intake of other foods. This diet increases carbohydrate intake while reducing the intake of all other nutrients, including fiber and antioxidant vitamins.

Excessive intake of carbohydrates and low fiber and antioxidants may aggravate glucose intolerance and increase the risk of diabetes. Rapidly absorbed carbohydrates, characterized by a high glycemic load, may aggravate glucose intolerance and increase metabolic disorder [31]. Consumption of high carbohydrate diets has been associated with high levels of fasting glucose and the risk of diabetes mellitus in Korean women [32]. In contrast, antioxidants nutrients are known to have a protective effect against the risk of diabetes by inhibiting the peroxidation chain reaction [33]. According to a prospective cohort study, vitamin C intake was significantly lower in cases of type 2 diabetes [34]. Fiber can also control or lower serum glucose by delaying glucose entry into the bloodstream and reducing the post-meal rise of serum glucose [35].

Stress has been suggested to be a risk factor for the development of diabetes. Stress is also often thought to be a consequence of diabetes. Diabetes patients have reported higher stress and greater depressive symptoms than healthy controls [36]. According to a meta-analysis, people with diabetes are two times more likely to have depression than people without diabetes [37]. It is known that the diagnosis of diabetes or the burden of dealing with its complications may lead to psychological stress [38]. This evidence suggests that the association between stress and diabetes is potentially bidirectional. However, because our analysis was cross-sectional, we could not determine the temporality of this association, and we are limited to discussing the aspects of diabetes risk due to stress. 
The present study has several limitations. First, whether stress is related to DVS and the risk of diabetes was analyzed using a cross-sectional study, and the cause-effect could not be established. Second, we used SQFFQ to estimate the participant's dietary intake, which could be an inaccurate method of quantifying the exact amounts of food consumed. Well-trained interviewers with a validated SQFFQ and pictures of portion sizes conducted the survey, but measurement error in dietary intake seems inevitable [19]. Nevertheless, to our knowledge, this is the first study to examine the association between stress and the risk of type 2 diabetes in relation to dietary variety.

\section{Conclusions}

The present study used data from KoGES to demonstrate that high levels of psychological stress are associated with the risk of type 2 diabetes in Korean adults. Highly stressed individuals with a low variety of dietary intake showed a higher OR for diabetes compared with those with lower stress levels and higher DVS. Therefore, psychological stress accompanied by a low-variety diet is partially related to diabetes risk.

Author Contributions: Conceptualization, Y.K.; formal analysis, Y.S.; investigation, Y.S.; supervision, Y.K.; writing—original draft, Y.S. All authors have read and agreed to the published version of the manuscript.

Funding: This study was supported by the National Research Foundation of Korea (NRF) funded by the Korean Government (MSIT) (No. 2012M3A9C4048761 and 2019R1C1C1002649).

Acknowledgments: Data in this study were from the Korean Genome and Epidemiology Study (KoGES; 4851-302), the National Research Institute of Health, the Centers for Disease Control and Prevention, and the Ministry for Health and Welfare, Republic of Korea.

Conflicts of Interest: The authors declare no conflict of interest.

\section{References}

1. Selye, H. The Stress of Life, Revise ed.; McGraw-Hill: New York, NY, USA, 1978.

2. McEwen, B.S. Stress, Adaptation, and Disease: Allostasis and Allostatic Load. Ann. N. Y. Acad. Sci. 1998, 840, 33-44. [CrossRef] [PubMed]

3. Wild, S.; Roglic, G.; Green, A.; Sicree, R.; King, H. Global Prevalence of Diabetes: Estimates for the Year 2000 and Projections for 2030. Diabetes Care 2004, 27, 1047-1053. [CrossRef] [PubMed]

4. Ministry of Health and Welfare of Korea. Korea Health Statistics 2013: Korea National Health Nutrition Examination Survey (KNHANES VI-1); Korea Centers for Disease Control and Prevention: Daejeon, Korea, 2014.

5. Huang, X.; Pan, J.; Chen, D.; Chen, J.; Chen, F.; Hu, T. Efficacy of Lifestyle Interventions in Patients with Type 2 Diabetes: A Systematic Review and Meta-Analysis. Eur. J. Intern. Med. 2016, 27, 37-47. [CrossRef] [PubMed]

6. Oldewage-Theron, W.H.; Kruger, R. Food Variety and Dietary Diversity as Indicators of the Dietary Adequacy and Health Status of an Elderly Population in Sharpeville, South Africa. J. Nutr. Elder. 2008, 27, 101-133. [CrossRef] [PubMed]

7. US Department of Agriculture; US Department of Health and Human Services. Nutrition and Your Health: Dietary Guidelines for Americans; Home and Garden Bulletin No. 232; USDA: Wachington, DC, USA, 1995.

8. Sandström, B.; Lyhne, N.; Pedersen, J.; Aro, A.; Thorsdóttir, I.; Becker, W. Nordiska Näringsrekommendationer 1996 (Nordic Nutrition Recommendations); Nordic Council of Ministers, Nord: Copenhagen, Denmark, 1996.

9. Azadbakht, L.; Esmaillzadeh, A. Dietary Diversity Score is Related to Obesity and Abdominal Adiposity among Iranian Female Youth. Public Health Nutr. 2011, 14, 62-69. [CrossRef]

10. Azadbakht, L.; Mirmiran, P.; Azizi, F. Dietary Diversity Score is Favorably Associated with the Metabolic Syndrome in Tehranian Adults. Int. J. Obes. 2005, 29, 1361-1367. [CrossRef]

11. Azadbakht, L.; Mirmiran, P.; Esmaillzadeh, A.; Azizi, F. Dietary Diversity Score and Cardiovascular Risk Factors in Tehranian Adults. Public Health Nutr. 2006, 9, 728-736. [CrossRef]

12. Garavello, W.; Giordano, L.; Bosetti, C.; Talamini, R.; Negri, E.; Tavani, A.; Maisonneuve, P.; Franceschi, S.; La Vecchia, C. Diet Diversity and the Risk of Oral and Pharyngeal Cancer. Eur. J. Nutr. 2008, 47, 280-284. [CrossRef] 
13. Novak, M.; Björck, L.; Giang, K.W.; Heden-Ståhl, C.; Wilhelmsen, L.; Rosengren, A. Perceived Stress and Incidence of Type 2 Diabetes: A 35-year Follow-up Study of Middle-aged Swedish Men. Diabet. Med. 2013, 30, e8-e16. [CrossRef]

14. KATo, M.; NoDA, M.; INoue, M.; KADowAKI, T.; Tsugane, S. Psychological Factors, Coffee and Risk of Diabetes Mellitus among Middle-Aged Japanese: A Population-Based Prospective Study in the JPHC Study Cohort. Endocr. J. 2009, 56, 459-468. [CrossRef]

15. Kim, Y.; Han, B.; KoGES Group. Cohort Profile: The Korean Genome and Epidemiology Study (KoGES) Consortium. Int. J. Epidemiol. 2016, 46, e20. [CrossRef] [PubMed]

16. Goldberg, D. Manual of the General Health Questionnaire; NFER Nelson: Winsdor, UK, 1978.

17. Chang, S. Standardization of Collection and Measurement for Heath Data; The Korean Society for Preventive Medicine: Seoul, Korea, 2000; pp. 121-159.

18. Ahn, Y.J.; Lee, J.E.; Paik, H.Y.; Lee, H.K.; Jo, I.H.; Kim, K.C. Development of a Semi-quantitative Food Frequency Questionnaire Based on Dietary Data from the Korea National Health and Nutrition Examination Survey. Nutr. Sci. 2003, 6, 173-184.

19. Ahn, Y.; Kwon, E.; Shim, J.E.; Park, M.K.; Joo, Y.; Kimm, K.; Park, C.; Kim, D.H. Validation and reproducibility of food frequency questionnaire for Korean genome epidemiologic study. Eur. J. Clin. Nutr. 2007, 61, 1435-1441. [CrossRef] [PubMed]

20. Korean Nutrition Society. Recommended Dietary Allowances for Koreans, 7th ed.; Korean Nutrition Society: Seoul, Korea, 2000.

21. Randall, E.; Marshall, J.; Graham, S.; Brasure, J. Frequency of Food use Data and the Multidimensionality of Diet. J. Am. Diet. Assoc. 1989, 89, 1070-1075. [PubMed]

22. Choi, Y.; Kim, S.; Jung, K.; Chang, Y. The Analysis of the Factors Related to Diet Quality in the Postmenopausal Women. J. Nutr. Health 2002, 35, 102-114.

23. Zimmet, P.; Alberti, K.; Shaw, J. Global and Societal Implications of the Diabetes Epidemic. Nature 2001, 414, 782-787. [CrossRef]

24. Friedewald, W.T.; Levy, R.I.; Fredrickson, D.S. Estimation of the Concentration of Low-Density Lipoprotein Cholesterol in Plasma, without use of the Preparative Ultracentrifuge. Clin. Chem. 1972, 18, 499-502. [CrossRef]

25. Twig, G.; Gerstein, H.C.; Fruchter, E.; Shina, A.; Afek, A.; Derazne, E.; Tzur, D.; Cukierman-Yaffe, T.; Amital, D.; Amital, H. Self-Perceived Emotional Distress and Diabetes Risk among Young Men. Am. J. Prev. Med. 2016, 50, 737-745. [CrossRef]

26. Wiernik, E.; Nabi, H.; Thomas, F.; Pannier, B.; Hanon, O.; Simon, T.; Simon, J.; Danchin, N.; Limosin, F.; Czernichow, S. Association between Current Perceived Stress and Incident Diabetes is Dependent on Occupational Status: Evidence from the IPC Cohort Study. Diabetes Metab. 2016, 42, 328-335. [CrossRef]

27. Nyberg, S.T.; Fransson, E.I.; Heikkila, K.; Ahola, K.; Alfredsson, L.; Bjorner, J.B.; Borritz, M.; Burr, H.; Dragano, N.; Goldberg, M.; et al. Job Strain as a Risk Factor for Type 2 Diabetes: A Pooled Analysis of 124,808 Men and Women. Diabetes Care 2014, 37, 2268-2275. [CrossRef]

28. Foote, J.A.; Murphy, S.P.; Wilkens, L.R.; Basiotis, P.P.; Carlson, A. Dietary Variety Increases the Probability of Nutrient Adequacy among Adults. J. Nutr. 2004, 134, 1779-1785. [CrossRef] [PubMed]

29. Takeda, E.; Terao, J.; Nakaya, Y.; Miyamoto, K.; Baba, Y.; Chuman, H.; Kaji, R.; Ohmori, T.; Rokutan, K. Stress Control and Human Nutrition. J. Med. Investig. 2004, 51, 139-145. [CrossRef] [PubMed]

30. De Vriendt, T.; Clays, E.; Huybrechts, I.; De Bourdeaudhuij, I.; Moreno, L.A.; Patterson, E.; Molnár, D.; Mesana, M.I.; Beghin, L.; Widhalm, K. European Adolescents' Level of Perceived Stress is Inversely Related to their Diet Quality: The Healthy Lifestyle in Europe by Nutrition in Adolescence Study. Br. J. Nutr. 2012, 108, 371-380. [CrossRef] [PubMed]

31. Liu, S.; Manson, J.E. Dietary Carbohydrates, Physical Inactivity, Obesity, and the 'metabolic Syndrome'as Predictors of Coronary Heart Disease. Curr. Opin. Lipidol. 2001, 12, 395-404. [CrossRef]

32. Park, S.; Lee, K.; Park, H. Dietary Carbohydrate Intake is Associated with Cardiovascular Disease Risk in Korean: Analysis of the Third Korea National Health and Nutrition Examination Survey (KNHANES III). Int. J. Cardiol. 2010, 139, 234-240. [CrossRef]

33. Gutteridge, J.M.; Halliwell, B. Free Radicals in Biology and Medicine; Clarendon Press: Oxford, UK, 1985. 
34. Feskens, E.J.; Virtanen, S.M.; Rasanen, L.; Tuomilehto, J.; Stengard, J.; Pekkanen, J.; Nissinen, A.; Kromhout, D. Dietary Factors Determining Diabetes and Impaired Glucose Tolerance. A 20-Year Follow-Up of the Finnish and Dutch Cohorts of the Seven Countries Study. Diabetes Care 1995, 18, 1104-1112. [CrossRef]

35. Chandalia, M.; Garg, A.; Lutjohann, D.; Von Bergmann, K.; Grundy, S.M.; Brinkley, L.J. Beneficial Effects of High Dietary Fiber Intake in Patients with Type 2 Diabetes Mellitus. N. Engl. J. Med. 2000, 342, 1392-1398. [CrossRef]

36. Steptoe, A.; Hackett, R.A.; Lazzarino, A.I.; Bostock, S.; La Marca, R.; Carvalho, L.A.; Hamer, M. Disruption of Multisystem Responses to Stress in Type 2 Diabetes: Investigating the Dynamics of Allostatic Load. Proc. Natl. Acad. Sci. USA 2014, 111, 15693-15698. [CrossRef]

37. Anderson, R.J.; Freedland, K.E.; Clouse, R.E.; Lustman, P.J. The Prevalence of Comorbid Depression in Adults with Diabetes: A meta-analysis. Diabetes Care 2001, 24, 1069-1078. [CrossRef]

38. Talbot, F.; Nouwen, A. A Review of the Relationship between Depression and Diabetes in Adults: Is There a Link? Diabetes Care 2000, 23, 1556-1562. [CrossRef]

(C) 2020 by the authors. Licensee MDPI, Basel, Switzerland. This article is an open access article distributed under the terms and conditions of the Creative Commons Attribution (CC BY) license (http://creativecommons.org/licenses/by/4.0/). 